\title{
Added value of sending photograph in diagnosing a medical disease declared at sea: experience of the French Tele-Medical Assistance Service
}

\author{
Emilie Dehours, Alexandre Saccavini, Pierre Roucolle, Patrick Roux, Vincent Bounes
}

Centre de Consultations Médicales Maritimes, French TMAS, SAMU 31, Hôpital Purpan, CHU Toulouse, France

\begin{abstract}
The maritime medical tele-consultation carried out by a doctor from the Toulouse Tele-Medical Assistance Service is currently based on tele-consultation using radiotelegraphy and the complementary transmission of data (photographs, electrocardiogram) via the Internet. In a previous article, we presented the benefits of photograph transmission for trauma management in isolated areas. Through this new series of cases, we wanted to expose the aspect of the medical pathologies and the contribution of sending photographs in their management.

Case reports: Case 1. Myocardial infarction. Case 2. Toxic epidermal necrolysis. Case 3. Tooth abscess. Case 4. Shingles. Case 5. Junctional tachycardia.

The tele-transmission of photographs provides a real diagnostic and follow-up tool for patients suffering from medical pathologies. The constant increase in the number of tele-consultations with the exchange of photographs shows its necessity and the interest of the participants in the development of these technologies.

(Int Marit Health 2017; 68, 2: 122-125)
\end{abstract}

Key words: French TMAS, tele-consultation, maritime, photograph, medical

\section{INTRODUCTION}

Physicians at the French Tele-Medical Assistance Service (TMAS) in Toulouse are obliged to carry out tele-medical assistance for any persons on board a vessel, whether the pathology is medical or traumatic. In a previous article [1], we presented the benefits of photograph transmission for trauma management in isolated areas. The aim of presenting this series of cases is to present different cases of medical pathologies that could be diagnosed or followed up, despite the patient being isolated in a maritime environment, thanks to the transmission of photographs.

\section{CASE 1}

The captain of a fishing trawler off the Kerguelen Islands called the French TMAS regarding one of the fishermen on board. Mr K., 48 years old, from Madagascar presented with oppressive medio-thoracic pain for 16 hours. The patient had no significant clinical history, and was not being treated for anything chronic. Clinical examination found a symmetrical pulse without sign of right or left cardiac decompensation, blood pressure was 117/85 mm Hg, heart rate was $95 \mathrm{bpm}$. The vessel did not have an electrocardiograph. Faced with the high probability of a diagnosis of angina, the captain, under the recommendations of the French TMAS physician, changed course towards to another vessel equipped with this equipment. Meanwhile, the patient benefited from treatment with trinitrin spray, partially effective on the intensity of pain and acetylsalicylic acid $250 \mathrm{mg}$ per os. Twenty-four hours after re-routing, an electrocardiogram was performed on board another vessel (Fig. 1A) which found an extensive anterior infarction with the presence of a $Q$ wave and a current of sub-epicardial lesion. With this new element of information, the treatment was supplemented with clopidogrel $600 \mathrm{mg}$ then $75 \mathrm{mg}$ daily, a trinitrin patch, a curative dose of calciparin, and propranolol $40 \mathrm{mg}$ per day. The patient was then seen by the Ker- 


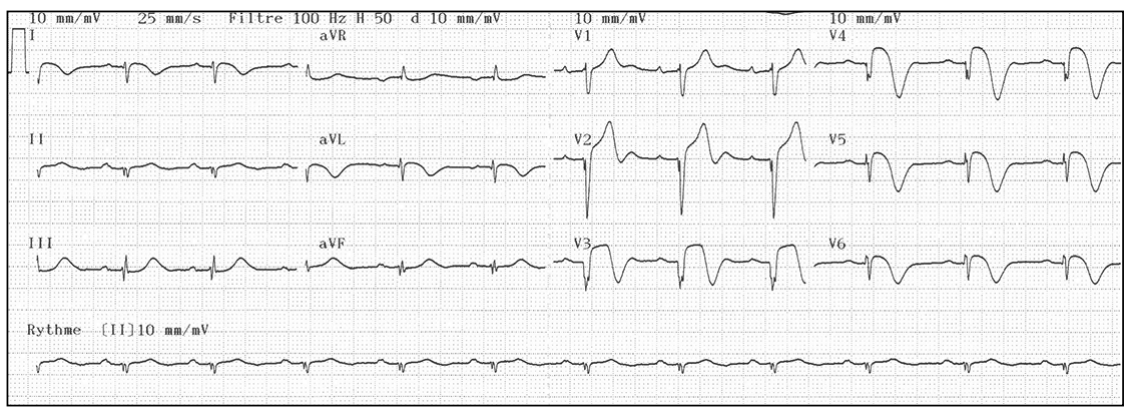

Figure 1A. Myocardial infarction at day 1

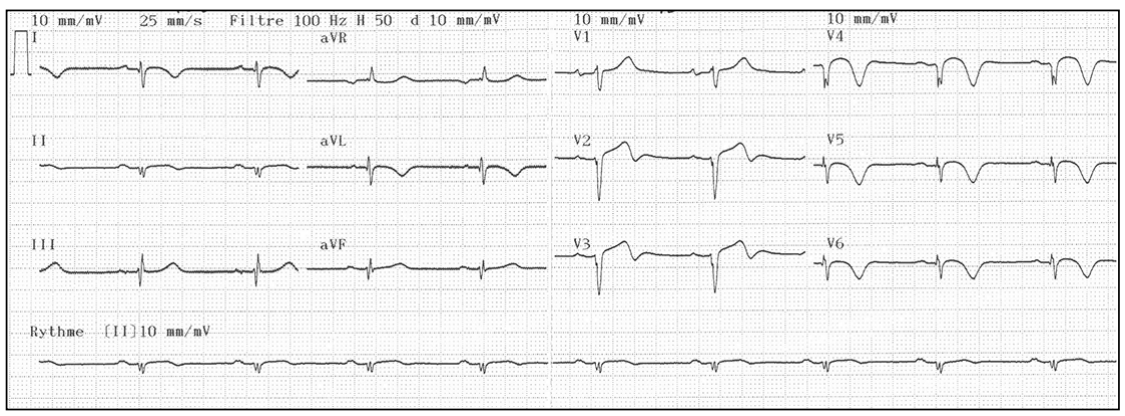

Figure 1B. Myocardial infarction at day 4

guelen Islands doctor who sent a second electrocardiogram (Fig. 1B) and a medical check-up (appearance of bursts of ventricular extrasystoles) which allowed the patient's treatment to be adapted, with, in particular, a decrease in the dose of propranolol. The patient was then evacuated by an Australian fisheries surveillance vessel. Fourteen days after the onset of chest pain the patient was hospitalised in the Saint Denis hospital on the Island of Reunion. The transmission of electrocardiograms enabled the patient to receive a medical diagnosis, treatment and follow-up until he arrived at a cardiology department adapted to the severity of his pathology.

\section{CASE 2}

The French nurse of a cross-channel ferry called about a 52-year-old English passenger regarding suspected burning of the lower limbs (Fig. 2). The clinical examination performed by the nurse at the time of the call to the French TMAS found a purpuric eruption in the two lower limbs associated with the presence of blisters and a positive $\mathrm{Ni}$ kolsky's sign. The patient was asthenic, with no fever and with normal haemodynamic parameters. Interviewing the patient eliminated recent exposure to the sun. Given the severity of the lesions visible in the photograph, the French TMAS physician was able to determine the cause of the lesions through an in-depth interrogation. This hypertensive patient had indeed been treated with ezetimibe and losartan and his doctor recently prescribed him nifedipine. A diagnosis of toxic epidermal necrolysis due to nifedipine was made. The patient was then evacuated by medical helicopter to the Le Havre Hospital Centre resuscitation department.

\section{CASE 3}

On board a supply ship off Angola, a 46-year-old French sailor presents with oedema of the face located on the left cheek (Fig. 3A) for 24 hours. The clinical examination carried out by the on-board caregiver during the call found dental pain (tooth no. 24) and an abscess facing root 24 (Fig. 3B). Receiving the photographs allowed the French TMAS physician to diagnose cellulitis of the face, probably of dental origin. He prescribed probabilistic antibiotic therapy with amoxicillin and clavulanic acid $1 \mathrm{~g}$ three times a day and recommended the patient disembark the boat before the infection became severe so that he could receive dental care.

\section{CASE 4}

The captain of an oil tanker, positioned across the Azores, called on behalf of his 50-year-old chef, who presented with a thoracic eruption associated with intense pruritus progressing for 7 days. Local examination carried out by the captain was poor, and he was unable to describe the cutaneous lesion. The general examination was normal, the patient was apyretic. The French TMAS physician asked the captain to send a photograph (Fig. 4A). This revealed 


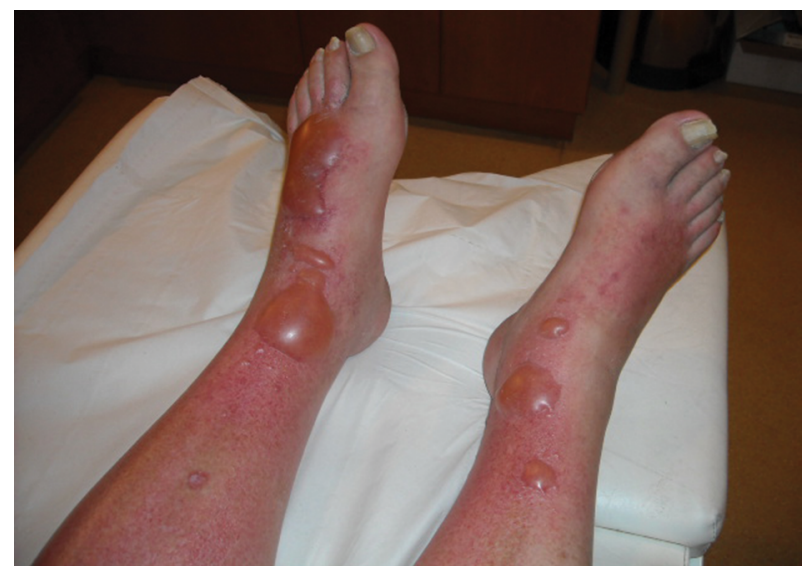

Figure 2. Toxic epidermal necrolysis

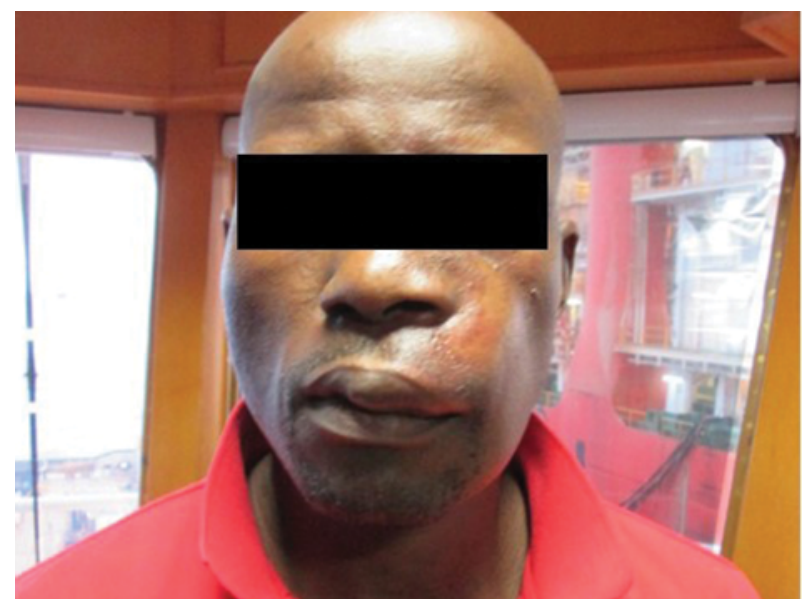

Figure 3A. Facial cellulitis

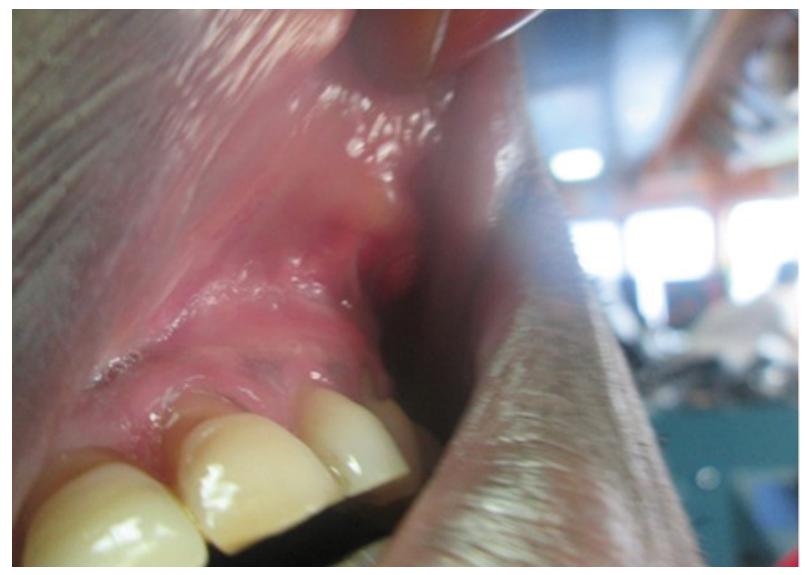

Figure 3B. Tooth abscess

a vesicular eruption of metameric distribution, and made it possible to make the diagnosis of shingles. The patient was treated with acyclovir $1 \mathrm{~g}$ per day for 10 days and deslorata-

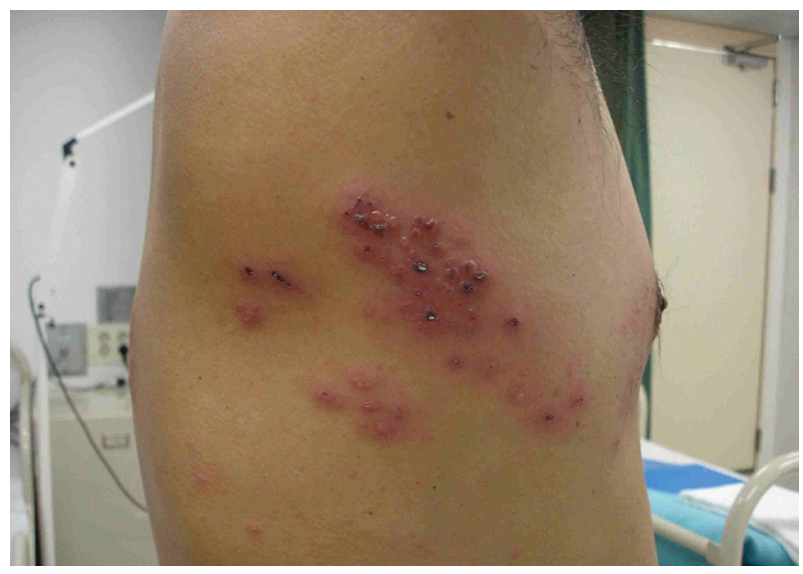

Figure 4A. Shingles at day 1

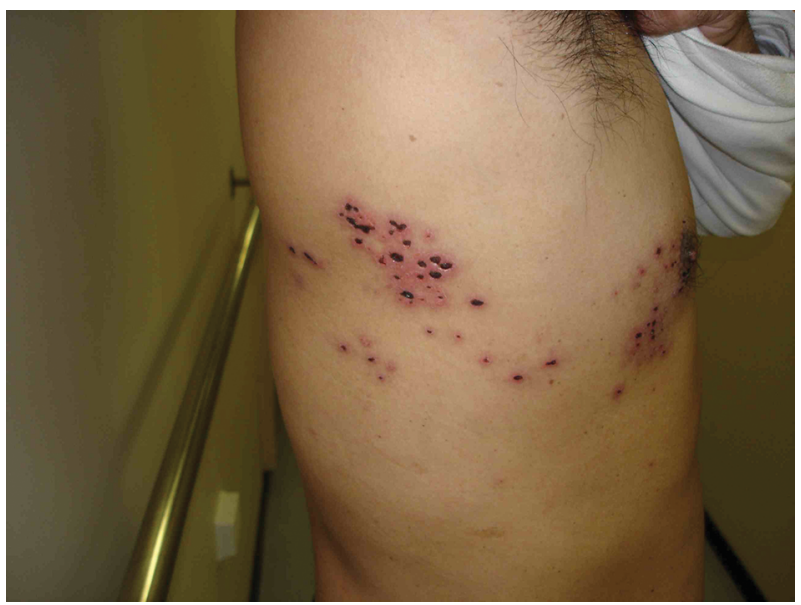

Figure 4B. Shingles at day 4

dine $5 \mathrm{mg}$ per day with an anti-pruritic agent. The patient remained on board under clinical supervision of the captain who sent a photograph of the evolution of the rash after 4 days of treatment (Fig. 4B). When the patient disembarked the vessel, no sequelae were found.

\section{CASE 5}

A 27-year-old student from a passenger ship located between Barbados and Guyana came to the on-board infirmary with a feeling of malaise and palpitations. She was taken care of by the doctor on board. Clinical examination revealed a tachycardia at $220 \mathrm{bpm}$ and blood pressure at 110/80 $\mathrm{mm} \mathrm{Hg}$. The electrocardiogram showed supra ventricular tachycardia (Fig. 5). The patient was then treated with propranolol $40 \mathrm{mg}$, 1 tablet and amiodarone $200 \mathrm{mg}, 4$ tablets. The control electrocardiogram (not available) performed 4 hours after the initiation of treatment revealed a regular sinus rhythm with a frequency of 80, a normal axis without conduction or repolarisation disorder. The doctor on board then called the French 


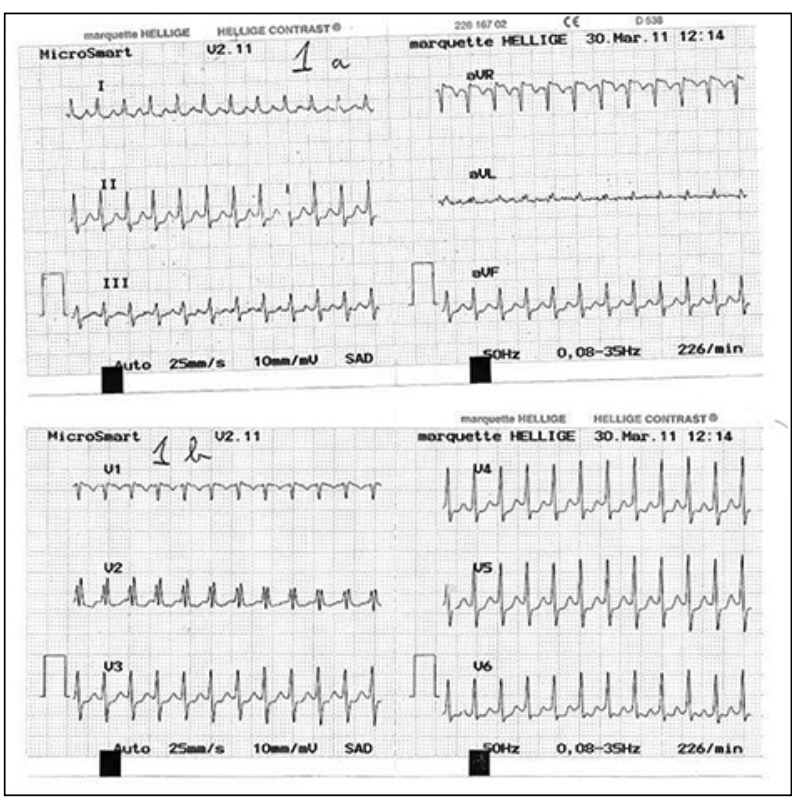

Figure 5. Junctional tachycardia

TMAS to seek expert advice. The French TMAS physician got a second opinion from the attending cardiologist at Toulouse University Hospital. Transmission of the patient's record and her electrocardiogram per crisis in particular allowed the cardiologist to confirm a diagnosis of Bouveret's disease junctional tachycardia, to prescribe treatment with amiodarone $200 \mathrm{mg}, 1$ tablet per day, and to indicate the need for the patient to have a cardiology consultation upon her return to France so she could undergo radiofrequency ablation.

\section{DISCUSSION}

The regulatory framework of the French TMAS is defined in the interministerial instruction [2] on the operational organisation of medical aid at sea (aide médicale en mer AMM) of 29 April, 1983 and in the Prime Minister's instructions of 2011 [3]. They define the missions of the French TMAS, which must provide a permanent maritime tele-medical consultations and assistance service. The action of the French TMAS also contributes to the health policy of the Directorate for Maritime Affairs and the Special Scheme for the Social Security of Seafarers (ENIM), which aims, in particular, to provide seafarers with the best possible quality care during sea voyages and thus limit the possible consequences of illness or injury on board.

In order to carry out these missions, the French TMAS interacts with those responsible for medical care on board, who have access to medical supplies determined by the type of navigation practised, the number and quality of the persons present on board and the remoteness of medical assistance. It is defined by division 217 , sanitary and medical provisions [4]. These on board caregivers receive specific training [5] which should enable them to cope autonomously with mild clinical problems as well as more complex medical problems in general medicine or emergency medicine that require a tele-consultation. This tele-consultation can be facilitated as in the cases presented here by sending photographs. The first case mentioned that involved an electrocardiogram being sent allowed the diagnosis, specific treatment and evacuation of the patient to a specialised service. The second case shows the interest of sending a photograph regarding a rare and serious diagnosis. The photographs from the third case allowed the doctor to land the patient as he needed specialised care from a dentist. The fourth case legitimises sending photographs in the event of dermatological disorders and when faced with the difficulty of describing the lesions. The fifth case shows the appeal of sending an electrocardiogram, especially when specialised advice is required.

\section{CONCLUSIONS}

The tele-transmission of photographs has already improved the quality of our maritime medical tele-consultations, for both traumatic and medical pathologies. Developing video conferencing will probably be the next step in advancing our practices.

\section{CONFLICT OF INTEREST}

All authors declare that they have no conflicts of interest.

\section{REFERENCES}

1. Dehours E, Tourneret ML, Roux $P$, et al. Benefits of photograph transmission for trauma management in isolated areas: cases from the French Tele-Medical Assistance Service. Int Marit Health. 2016; 67(2): 83-87, doi: 10.5603/IMH.2016.0017, indexed in Pubmed: 27364173.

2. Instruction interministérielle relative à l'organisation opérationnelle de l'aide médicale en mer du 29 avril 1983. http://www.secourisme.info/pdf/txt595. (19 février 2016).

3. Instruction premier ministre du 29 aout 2011 relative à l'organisation de l'aide médicale en mer. http://circulaires.legifrance.gouv. $\mathrm{fr} / \mathrm{pdf} / 2011 / 11 / \mathrm{cir}$ 34077. (19 février 2016).

4. J.O. du 20 novembre 1996, Division 217, dispositions sanitaires et médicales. http://www.developpement-durable.gouv.fr/IMG/ pdf/d217_30-12-15. (19 février 2016).

5. Arrêté du 2 juillet 1999 relatif à la formation médicale des personnels servant à bord des navires de commerce et de plaisance armés avec un rôle d'équipage. https://www.legifrance.gouv.fr/ affichTexte.do? (19 février 2016). 